\title{
PENGEMBANGAN PERANGKAT PEMBELAJARAN MODEL ACCELERATED LEARNING DENGAN STRATEGI FIRING LINE UNTUK MELATIH DISPOSISI MATEMATIS SISWA
}

\author{
Cindy Amelia Yulianingrum ${ }^{1}$, Agus Prasetyo Kurniawan², Ahmad Lubab ${ }^{3}$ \\ ${ }^{1,2,3}$ Universitas Islam Negeri Sunan Ampel, Surabaya \\ cindy.amelia0407@gmail.com ${ }^{1}$, tyo@uinsby.ac.id ${ }^{2}$, ahmadlubab@uinsby.ac.id ${ }^{3}$
}

Received 6 February 2020; revised 14 June 2020; accepted 22 June 2020.

\begin{abstract}
ABSTRAK
Penelitian ini mengembangkan perangkat pembelajaran berupa Rencana Pelaksanaan Pembelajaran (RPP) dan Lembar Kerja Peserta Didik (LKPD) disesuaikan model accelerated learning dengan strategi firing line. Tujuan penelitian ini adalah untuk mengetahui 1) kevalidan RPP dan LKPD, 2) kepraktisan RPP dan LKPD, 3) keefektifan RPP dan LKPD, dan 4) disposisi matematis. RPP dan LKPD dikembangkan menggunakan model pengembangan ADDIE yang meliputi fase analisis, fase perencanaan, fase pengembangan, fase penerapan, dan fase penilaian. Uji coba perangkat dilakukan pada tanggal 22 s.d 23 Agustus 2019 di MTsN 1 Kota Surabaya. Instrumen uji coba perangkat berupa lembar catatan lapangan, lembar angket validasi, lembar observasi dan lembar angket. Hasil analisis data berupa RPP dan LKPDdengan rata-rata secara berturut-turut 4,30 dan 4,31. RPP dan LKPD tergolong praktis dan mendapat nilai B (layak digunakan dengan sedikit revisi). Aktivitas siswa tergolong aktif,dengan rata-rata 89,58\% pada pertemuan pertama dan rata-rata pertemuan kedua sebesar 93,50\%, Selain itu, dilihat dari keterlaksanaan sintaksnya, kedua pertemuan memperoleh rata-rata sebesar $80 \%$ dan $84,71 \%$. Selain itu, RPP dan LKPD yang dikembangkan tergolong efektif. Dengan demikian, disposisi matematis pada mayoritas siswa kelas VIII H MTsN 1 Kota Surabaya tergolong cukup baik.
\end{abstract}

Kata kunci: accelerated learning, disposisi matematis, firing line

\begin{abstract}
This research is to develop teaching administrations namely lesson plan (RPP) and students' worksheet (LKPD) which had addapted from accelerated learning model combined firing line strategy. This research attemp to identify 1) RPP and LKDP validity, 2) RPP and LKPD practicability, 3) the effectiveness of RPP and LKPD, 4) students' mathematical disposition. RPP and LKPD were developed using ADDIE developing model which is divided into some phases namely; analysis, planning, developing, applying and assessing. Teaching administration test was
\end{abstract}


done on August $22^{\text {nd }}$ and $23^{\text {rd }}, 2019$ in MTsN 1 Surabaya. Data of the research were collected by field note, validation questionnaire, observation guidelines, and questionnaire. Result of the analysis data are; The developed RPP and LKDP are categorized as valid teaching administrations with 4.30 and 4.31 on average in a row. RPP and LKDP are categorized as practicability teaching administrations and had B grade (applicable with a few revision). Student participation categorized as active with $89.58 \%$ average in the first meeting and $93.50 \%$ average in the second meeting. Moreover, reviewed from the syntax implementation, it gained $80 \%$ and $84.71 \%$ on its average. Therefore, the developed RPP and LKPD is effectively applied in teaching and learning process. Furthermore, mathematical disposition of most students at VIII H class in MTsN 1 Surabaya is quite good.

Keywords: accelerated learning, mathematical disposition, firing line

\section{PENDAHULUAN}

Belajar matematika membutuhkan kemampuan kognitif dan kemampuan afektif.Kemampuan kognitif dapat dilakukan dengan cara berpikir dan mengkonstruk pengetahuan pada kegiatan mengingat, memecahkan masalah, dan mengambil keputusan. Menurut Muslim (2016) kemampuan afektif digunakan oleh individu untuk menyelesaikan masalah yang ditinjau dari sikap dan nilai untuk sebagai tolok ukur keberhasilan. Didukung oleh pendapat Fauziah dkk (2017) bahwa aspek afektif pada pembelajaran matematika menjadi tolak ukur penting untuk dilatihkan, karena sebagai penunjangaspek kognitif siswa untuk menyelesaikan masalah matematis. Sugandi (2015) juga berpendapat salah satu kemampuan afektif yang memiliki peranan penting dalam pembelajaran matematika adalah kemampuan disposisi matematis. Rahman (2015) juga berpendapat bahwa disposisi matematis diperlukan oleh siswa untuk tekun mencobamenyelesaikan masalah, bertanggung jawab ketika belajar, dan mengembangkan kebiasaan yang baik ketika belajar matematika.

Risti (2018) berpendapat disposisi matematis adalah kecenderungan siswa untuk berpikir dan bertindak secara positif saat belajar matematika. Didukung oleh Naryaningsih (2018) yang membuktikan bahwa disposisi siswa tidak dapat dipisahkan dari pengetahuan matematika. Disimpulkan bahwa disposisi matematis adalah sikap positif yang dimiliki oleh siswa dan digunakan pada kegiatan berpikir dan bertindak selama belajar matematika. 
Sejalan dengan penelitian yang dilakukan oleh Syaban bahwa disposisi matematis siswa belum sepenuhnya tercapai dikarenakan kurangnya antusias siswa dalam belajar matematika. Didukung pendapat Nizzaruddin (2017) bahwa siswa kurang tertarik terhadap matematika, dan menganggap matematika itu pelajaran yang sulit untuk dipahami. Herawati (2017) pada hasil penelitiannya menyatakan bahwa siswa memiliki sikap positif cenderung memiliki kemampuan matematis yang baik dan disposisi matematis siswa dinyatakan baik, sedangkan siswa yang memiliki kemampuan matematis kurang baik akan cenderung bersikap negatif terhadap matematika dan disposisi matematis siswa rendah.

Sugandi (2015) berpendapat terdapat dua disposisi yaitu disposisi positif dan disposisi negatif, yang sejalan dengan pendapat Killpatrick dkk (2001) bahwa disposisi matematis menjadikan siswa cenderung pasif dan tidak antusias saat belajar matematika dan siswa tidak dapat menyelesaikan masalah matematika dengan tepat. Untuk itu dilakukan upaya melatihkan disposisi matematis siswa menggunakan model pembelajaran kooperatif dan strategi pembelajaran yang aktif.

Model pembelajaran kooperatif yang memiliki potensi untuk melatihkan disposisi matematis yaitu model pembelajaran accelerated learning. Pembelajaran accelerated learning merupakan pembelajaran yang sesuai digunakan untuk menyampaikan materi pembelajaran dengan tepat dan cepat, penggunaan waktu yang singkat. Kurnia (2017) menjelaskan langkah pembelajaran dari model pembelajaran accelerated learningmenggunakan tipe MASTER yang terdapat 6 langkah pembelajaran yang harus dilakukan meliputi: motivation your mind (memotivasi pikiran siswa), acquiring the information (memperoleh informasi), searching out the meaning (mencari makna), triggering the memory (memicu memori), exbihiting what you know (menunjukkan kemampuan yang dimiliki), reflecting how you've learned (merefleksikan pembelajaran). Keenam langkah pembelajaran accelerated learning diharapkan dapat melatihkan disposisi matematis kepada siswa. Selain menggunakan model pembelajaran, dalam pembelajaran juga membutuhkan strategi pembelajaran yang dijadikan penunjang untuk melatihkan disposisi matematis. 
Saputra (2015) mengemukakan pendapatnya terkait strategi pembelajaran aktif yang menjadi sarana penunjang untuk melatihkan disposisi matematis siswa dan merubah suasana belajar agarmenyenangkan strategi pembelajaran aktif yang digunakan yaitu strategi firing line. Strategi firing line memiliki ciri khusus meliputi guru menjelaskan kembali materi pembelajaran dan siswa mampu menjawab pertanyaan dari guru dengan cepat dan jawaban yang tepat. langkah pembelajaran pada strategi firing line yang menjadikan siswa lebih aktif, meliputi menentukan tujuan pembelajaran, menentukan kelompok, mengintruksi siswa untuk membuat pertanyaan dan penyelesaian, bertukar pertanyaan antar siswa, diskusi jawaban pertanyaan dan mempresentasikan hasil diskusi kelompok.

Pembelajaran dilakukan sesuai model accelerated learning dengan strategi firing line serta aspek disposisi matematis diharapkan dapat dipenuhi pada setiap langkah kegiatan pembelajaran. Langkah pertama kegiatan yang dilakukan yaitu memotivasi pikiran dan menentukan tujuan pembelajaran agar tampak disposisi percaya diri, dilanjutkan langkah kegiatan kedua yaitu memperoleh informasi dan menentukan kelompok dilakukan dengan kegiatan berkelompok agar tampak disposisi percaya diri, bekerjasama, berpikir fleksibel dan keingintahuan, dilanjutkan kegiatan pembelajaran selanjutnya yaitu mencari makna dan memicu memori dengan mengintruksi siswa untuk membuat pertanyaan beserta penyelesaian, kemudian bertukar pertanyaan agar tampak aspek disposisi berpikir fleksibel, dan langkah terakhir pada pembelajaran yaitu menunjukkan kemampuan yang dimiliki dan merefleksikan siswa dalam belajar dengan mendiskusikan jawaban dari pertanyaan yang telah dibuat dan mempresentasikan hasil diskusi kelompok agar tampak disposisi kepercayaan diri, berpikir fleksibel dan keingintahuan.

Sari (2018) pada hasil penelitiannya berpendapat bahwa strategi pembelajaran aktif dapat digunakan untuk meningkatkan pemahaman konsep matematis dan menumbuhkan sikap positif terhadap matematika. Didukung oleh peneilitian Purwaningrum (2016) dalam artikelnya bahwa kebiasaan dalam berpikir dan sikap yang baik. Berpikir dan sikap yang baik merupakan dasar untuk mengembangkan disposisi matematis siswa, sebab itu mengembangkan disposisi matematis dengan cara dilatihkan agar berkembang menjadi lebih baik. 
Menciptakan suasana pembelajaran yang tidak monoton, dapat dilakukan dengan melatihkan kebiasaan yang baik dengan menggunakan pembelajaran yang bervariasi. Didukung oleh pendapat Cahyani (2018) pada penelitiannya bahwa pembelajaran model accelerated learning menjadikan suasana kelas menjadi lebih aktif, menyenangkan, tidak membutuhkan waktu yang lama, karena siswa dapat merespon secara cepat instruksi yang diberikan guru.

\section{METODE PENELITIAN}

Penelitian ini termasuk penelitian pengembangan yang menghasilkan data kuantitatif dengan deskripsi data kualitatif. Model pengembangan yang digunakan menggunakan model ADDIE karena pada fase akhir ADDIE merupakan tahap evaluasi. MTs Negeri 1 Kota Surabaya menjadi tempat penelitian dan siswa kelas VIII H menjadi subjek penelitian pada Semester Gasal Tahun Ajaran 2019/2020 tepatnya pada bulan Agustus 2019 menggunakan materi koordinat kartesius. Data penelitian diperoleh melalui teknik pengumpulan data dan teknik analisis data. Teknik pengumpulan data dan instrumen pengumpulan data meliput teknik field note menggunakan instrument pengumpulan data berupa lembar catatan lapangan untuk mencatat proses dilakukannya pengembangan RPP dan LKPD, teknik angket dengan instrumennya berupa lembar angket validasi RPP dan lembar angket LKPD, serta lembar angket disposisi matematis dan teknik observasi dengan instrumennya berupa lembar observasi keterlaksanaan sintaks, observasi aktivitas siswa, observasi respon siswa saat pembelajaran. Teknik analisis data yang digunakan meliputi analisis field note, analisis kevalidan RPP dan LKPD, analisis kepraktisan RPP dan LKPD dan analisis keefektifan RPP dan LKPD.

Pengembangan perangkat pembelajaran menggunakan menggunakan model ADDIE terdiri dari lima fase. Fase pertama yaitu fase analisis (analysis) pada fase ini terbagi menjadi dua tahapan yaitu tahap analisis kurikulum dan analisis kebutuhan. Analisis kebutuhan memiliki fungsi untuk memperoleh data dan informasi mengenai masalah yang dialami siswa serta alternatif pemecahan masalah pada siswa tersebut, sedangkan analisis kurikulum memiliki fungsi untuk menyusun RPP dan LKPD yang dikembangkan agar sesuai dengan kurikulum yang berlaku. 
Fase yang kedua yaitu perancangan (design) memiliki fungsi untuk merancang, mengembangkan dengan membuat serta memodifikasi RPP dan LKPD sesuai dengan model accelerated learning dan strategi firing line serta memiliki tujuan akhir untuk melatihkan disposisi matematis kepada siswa dengan materi ajar yang digunakan yaitu materi koordinat kartesius. Fase yang ketiga yaitu fase pengembangan (development) berfungsi untuk mewujudkan rancangan RPP dan LKPD yang telah disesuaikan untuk menjadi produk nyata, setelah menjadi produk nyata kemudian dilakukan validasi oleh para ahli untuk mengetahui kevalidan RPP dan LKPD yang dikembangkan.

Selanjutnya, fase penerapan (implementation) dilakukan uji coba terhadap RPP dan LKPD yang dikategorikan valid oleh para ahli dan diujicobakan pada subjek penelitian. Fase terakhir yaitu fase penilaian (evaluation), fase ini memiliki fungsi untuk penilaian dari data hasil aktivitas siswa, respon siswa selama pembelajaran dan keterlaksanaan sintaks yang dilakukan oleh guru, serta menilai angket disposisi matematis siswa untuk melihat disposisi matematisnya. Bedasarkan rata-rata angket, disposisi matematis dikategorikan pada Tabel 1.

Tabel 1. Kategori Disposisi Matematis

\begin{tabular}{cc}
\hline Kategori & Rata-rata \\
\hline Tidak baik & $1 \leq x \leq 1,5$ \\
Kurang baik & $1,5<x \leq 2,5$ \\
Cukup baik & $2,5<x \leq 3,5$ \\
Baik & $3,5<x \leq 4,5$ \\
Sangat baik & $4,5<x \leq 5$ \\
\hline
\end{tabular}

\section{HASIL PENELITIAN DAN PEMBAHASAN}

Pengembangan RPP dan LKPD disesuaikan model accelerated learningdengan strategi firing line menggunakan model pengembangan ADDIE yang terdiri dari lima fase. Fase analisis terbagi menjadi dua tahap yaitu tahap analisis kurikulum dan tahap analisis kebutuhan, adapun rincian hasil analisis sebagai berikut: 1) tahap analisis kurikulum, menggunakan kurikulum 2013 akan tetapi model pembelajaran yang digunakan oleh guru kelas VIII H MTsN 1 Kota Surabaya masih menggunakan pembelajaran konvensional yang berpusat pada guru, sehingga berdampak pada siswa menjadi sedikit berinteraksi dengan teman sebaya, kurang percaya diri untuk bertanya maupun menyampaikan pendapat saat 
pembelajaran berlangsung; 2) tahap analisis kebutuhan dilakukan dengan menganalisis masalah atau hambatan yang sedang dialami oleh peserta didik mencangkup karakter siswa bahwasannya siswa kelas VIII H di MTsN 1 Kota Surabaya membutuhkan pelajaran yang sering berinteraksi dan berinteraksi dengan teman sebaya sehingga siswa menjadi lebih aktif di kelas, selain itu sikap individu yang masih terkategori kurang dalam hal percaya diri terhadap kemampuan yang dimiliki oleh siswa dan bekerjasama dengan kelompoknya. Permasalahan yang terjadi menjadi beberapa faktor penghambat mempelajari matematika. Cara yang dapat digunakan untuk meminimalisasi permasalahan yang menjadi penghambat dapat menggunakan model pembelajaran yang akan dikembangkan oleh peneliti dengan harapan siswa lebih berinteraksi dengan teman sebayanya, lebih percaya diri dalam berpendapat, bertanya dan tampil ketika presentasi di kelas. Kegiatan tersebut harus dilakukan secara berulang serta dilatihkan kepada siswa agar memiliki kebiasaan yang baik.

Fase perancangan digunakan menyusun RPP dan LKPD disesuaikan dengan model accelerated learning dengan strategi firing line serta bedasarkan masalah yang dialami oleh siswa terhadap pelajaran matematika. Uraian singkat mengenai RPP dan LKPD yang dirancag sebagai berikut: 1) RPP yang didesain digunakan untuk 4 jam pelajaran yang dilakukan selama dua kali pertemuan, setiap pertemuanya berdurasi 80 menit setara dengan 2 jam pelajaran. Materi yang digunakan sesuai dengan waktu penelitian yaitu materi koordinat kartesius tercantum pada KD 3 dan KD 4. Komponen utama RPP yang dirancang meliputi identitas sekolah, mata pelajaran, kelas atau semester, materi utama, alokasi waktu, kompetensi inti, tujuan pembelajaran, fakta, prinsip, prosedur, strategi pembelajaran, model pembelajaran, media atau alat pembelajaran, sumber belajar, langkah-langkah dalam pembelajaran dan penilaian hasil pembelajaran yang mengacu pada model pembelajaran accelerated learning dengan strategi firing line. 2) LKPD dikembangkan sesuai dengan model pembelajaran accelerated learning dengan strategi firing line berisi terkait mater koordinat kartesius. LKPD yang digunakan dalam penelitian terdiri dari cover depan; kolom identitas kelompok, kolom kompetensi inti, kolom indikator pencapaian kompetensi, petunjuk pengerjaan, lembar jawaban LKPD untuk menjawab setiap butir soal. 
Fase pengembangan digunakan untuk mengembangkan RPP dan LKPD yang telah dirancang sesuai dengan model pembelajaran accelerated learningdengan strategi firing Line, dan untuk mengetahui kevalidan dan kepraktisan RPP maupun LKPD diperlukan penilaian yang dilakukan oleh para ahli untuk memperoleh nilai kelayakan ketika diujicobakan dilapangan. Sebelum proses validasi RPP dan LKPD yang dilakukan oleh ahli, RPP dan LKPD didiskusikan dan dibimbing terlebih dahulu pada dosen pembimbing. Proses untuk memperoleh kevalidan dan kepraktisan RPP serta LKPD yang dikembangkan dimulai pada tanggal 1 s.d 20 Agustus 2019 yang dilakukan oleh 3 ahli dengan rincian 2 ahli dosen Pendidikan Matematika UIN Sunan Ampel Surabaya dan 1 guru matematika MTsN 1 Kota Surabaya.

Fase penerapan dilakukan uji coba terhadap siswa VIII H MTsN 1 Kota Surabaya sebagai subjek penelitian terhadap RPP dan LKPD yang telah memperoleh penilaian valid oleh ahli (validator) . fase penerapan RPP dan LKPD yang telah dikembangkan dilakukan sebanyak 2 pertemuan, masing-masing pertemuan berdurasi 80 menit sehingga durasi total pertemuan sebanyak 160 menit.

Fase evaluasi dilakukan dengan menilai hasil observasi siswa berupa aktivitas siswa selama kegiatan pembelajaran, langkah pembelajaran yang dilakukan oleh guru, dan respon siswa setelah pembelajaran menggunakan model pembelajaran accelerated learning dengan strategi firing Line, selain itu menilai hasil disposisi matematika dari angket yang telah diberikan sebelum dilakukan pembelajaran mengunakan model pembelajaran accelerated learning dengan strategi firing line, hal ini dilakukan untuk mengetahui kepraktisan dan keefektifan RPP dan LKPD yang dikembangkan.

Hasil validasi ahli digunakan untuk melihat RPP dan LKPD yang dikembangkan sesuai dengan model pembelajaran accelerated learning dengan strategi firing line dapat digunakan atau tidak dapat digunakan dalam kegiatan pembelajaran berlangsung. Penilaian ahli dilakukan oleh 3 ahli yang berasal 2 dosen Pendidikan Matematika UIN Sunan Ampel Surabaya dan 1 guru Matematika MTsN 1 Kota Surabaya. Rekapitulasi hasil validasi ahli terhadap RPP dan LKPD yang kembangkan dapat dilihat pada Tabel 2. 
Tabel 2. Rekapitulasi Hasil Validasi RPP dan LKPD

\begin{tabular}{lcccccc}
\hline Perangkat & \multicolumn{3}{c}{ Validator } & Rata-rata & Keterangan & Kriteria \\
\cline { 2 - 4 } & I & II & III & & & \\
\hline RPP & 4,06 & 4,94 & 4,06 & 4,30 & Valid & Baik \\
LKPD & 4,14 & 5 & 3,79 & 4,31 & Valid & Baik \\
\hline
\end{tabular}

RPP dan LKPD tergolong valid dengan rata-rata berturut-turut yaitu 4,30 dan 4,31 serta memiliki kriteria baik sehingga dapat digunakan di lapangan dengan sedikit revisi yang telah disesuaikan dengan model accelerated learning dan strategi firing line, saran untuk perbaikan RPP yang dikembangkan sesuai model accelerated learning dan strategi firing line tercantum pada Tabel 3.

Tabel 3. Saran Validator terhadap RPP

\begin{tabular}{|c|c|c|}
\hline No. & Catatan & Revisi \\
\hline 1. & $\begin{array}{l}\text { Kesalahan penulisan kata masih } \\
\text { terlalu banyak }\end{array}$ & $\begin{array}{l}\text { Memperbaiki kesalahan penulisan } \\
\text { kata }\end{array}$ \\
\hline 2. & $\begin{array}{l}\text { RPP yang dikembangkan hanya } 1 \\
\text { kali pertemuan, akan tetapi validator } \\
\text { menyarankan untuk pengembangan } \\
\text { perangkat pembelajaran sebanyak } 2 \\
\text { kali pertemuan }\end{array}$ & $\begin{array}{l}\text { Menambah pertemuan pada RPP } \\
\text { dan menambah cangkupan materi } \\
\text { yang digunakan, agar RPP yang } \\
\text { dikembangkan memenuhi dan } \\
\text { dapat digunakan selama } 2 \text { kali } \\
\text { pertemuan. }\end{array}$ \\
\hline 3. & $\begin{array}{l}\text { Rubrik penilaiannya belum terlalu } \\
\text { jelas pada spesifikasi penilaian. }\end{array}$ & $\begin{array}{l}\text { Telah direvisi dan lebih } \\
\text { spesifikasi pada } \\
\text { penilaiannya }\end{array}$ \\
\hline
\end{tabular}

Pada Tabel 3 telah ditunjukkan saran validator terhadap perbaikan RPP. Sedangkan, saran untuk perbaikan LKPD yang dikembangkan sesuai model accelerated learning dan strategi firing line tercantum pada Tabel 4.

Tabel 4. Saran Validator terhadap LKPD

\begin{tabular}{|c|c|c|}
\hline No. & Catatan & Revisi \\
\hline 1. & $\begin{array}{l}\text { Lembar jawaban pada LKPD belum } \\
\text { beri keterangan yang jelas sehingga } \\
\text { masih membingungkan. }\end{array}$ & $\begin{array}{l}\text { Lembar jawaban LKPD diberi } \\
\text { keterangan yang jelas. }\end{array}$ \\
\hline 2. & $\begin{array}{l}\text { Perintah pada soal dalam } \\
\text { LKPDmasih kurang jelas dan belum } \\
\text { sesuai dengan modelaccelerated } \\
\text { learning dan strategi firing line. }\end{array}$ & $\begin{array}{l}\text { Memperjelas perintah pada } \\
\text { lembar soal di LKPD dan } \\
\text { menyesuaikan dengan agar sesuai } \\
\text { dengan model accelerated } \\
\text { learning dan strategi firing line. }\end{array}$ \\
\hline 3 & $\begin{array}{l}\text { Jumlah soal yang dikembangkan } \\
\text { masih kurang dan belum sesuai } \\
\text { dengan indikator pencapaian yang } \\
\text { digunakan. }\end{array}$ & $\begin{array}{l}\text { Menambah soal yang sesuai } \\
\text { dengan indikator pencapaian } \\
\text { kompetensi yang digunakan. }\end{array}$ \\
\hline
\end{tabular}


Pengembangan RPP dan LKPD sesuai dengan model accelerated learning dan strategi firing line memiliki tujuan akhir yaitu untuk melatihkan disposisi matematis siswa. Disposisi matematis siswa dilihat pada saat pemberian angket diposisi, kemudian masing-masing siswa mengisi angket tersebut sesuai dengan kondisi mereka masing-masing, dalam angket berupa pernyataan positif maupun pernyataan negatif. Pengambilan subjek penelitian bedasarkan acak sampel melalui 3 kelompok dengan total anggota kelompok sebanyak 12 siswa. Rekapitulasi hasil disposisi matematis siswa sebelum diterapkannya model accelerated learning dan strategi firing line tercantum pada Tabel 5.

Tabel 5. Rekapitulasi Hasil Disposisi Matematis Siswa

\begin{tabular}{cccc}
\hline $\begin{array}{c}\text { Nama } \\
\text { Siswa }\end{array}$ & Total Skor & Rata-Rata & $\begin{array}{c}\text { Kategori Disposisi } \\
\text { Matematis }\end{array}$ \\
\hline MIF & 140 & 3,89 & Baik \\
MRF & 159 & 4,42 & Baik \\
RFA & 113 & 3,14 & Cukup Baik \\
FRN & 99 & 2,75 & Cukup Baik \\
SNA & 124 & 3,44 & Cukup Baik \\
AAJ & 98 & 2,72 & Cukup Baik \\
IFK & 83 & 2,31 & Kurang Baik \\
FZN & 89 & 2,47 & Kurang Baik \\
ARD & 130 & 3,61 & Baik \\
MSD & 109 & 3,03 & Cukup Baik \\
MTP & 109 & 3,03 & Cukup Baik \\
AA & 133 & 3,69 & Baik \\
\hline
\end{tabular}

Butir pertanyaan pada angket disposisi matematis sebanyak 36 butir pertanyaan mencangkup pertanyaan negatif maupun pertanyaan positif. Dari 12 siswa yang dijadikan subjek penelitian untuk dilatihkan disposisi matematisnya terbagi menjadi 3 kategori yang memiliki diposisi baik sebanyak 4 siswa, memiliki kategori diposisi cukup baik sebanyak 6 siswa dan memiliki kategori kurang baik sebanyak 2 siswa. Sejumlah 12 siswa tersebut diamati selama proses pembelajaran menggunakan model accelerated learning dengan strategi firing line selama 2 kali pertemuan untuk mengetahui disposisi matematis siswa tersebut. Disposisi matematis siswa pada pertemuan pertama tergolong pada ratarata memiliki disposisi matematis yang kurang baik, setelah dilakukannya pembelajaran menggunakan model accelerated learning dengan strategi firing line, disposisi siswa tersebut tergolong pada rata-rata memiliki disposisi yang cukup baik. Oleh karena itu, disposisi matematika harus sering dilatihkan kepada 
setiap siswa selama kegiatan pembelajaran agar siswa tersebut terlatih dan dapat mengembangkan disposisinya.

\section{SIMPULAN}

Hasil pengembangan RPP dan LKPD dinyatakan valid memperoleh kevalidan rata-rata RPP sebesar 4,30 dan kevalidan rata-rata LKPD sebesar 4,31. RPP dan LKPD dinyatakan praktis, berdasarkan penilaian oleh validator pada RPP dan LKPD memperoleh rata-rata B, sehingga dikategorikan RPP dan LKPD dapat digunakan dengan sedikit revisi. Hasil pengembangan RPP dan LKPD tergolong efektif pada aktivitas siswa aktif rata-rata di atas $80 \%$, sintaks terlaksana rata-rata diatas $75 \%$, respon positif siswa terhadap kegiatan pembelajaran rata-rata di atas $70 \%$. Aspek disposisi matematis yang dilatih yaitu aspek keingintahuan, berfikir fleksibel dan kepercayaan diri. Data disposisi matematis diperoleh dari pemberian angket dan diisi oleh siswa, kemudian diberi penilaian sesuai dengan pertanyaan positif maupun pertanyaan negatif sesuai dengan skor yang telah ditentukan sebelumnya, sehingga dari 25 siswa VIII H diambil 12 siswa yang menjadi fokus dalam uji coba perangkat, rata-rata disposisi matematis yang dimiliki oleh siswa VIII H MTsN 1 Kota Surabaya tergolong cukup baik.Saran untuk peneliti selanjutnya sebaiknya perangkat pembelajaran sesuai model accelerated learning dengan strategi Firing Line perlu diujicobakan pada kelas unggulan dengan memaksimalkan menggunakan indikator disposisi matematis yang lain, meliputi bertanggung jawab, antusias dan serius dalam belajar matematika, bekerjasama dan berbagi dalam kegiatan belajar matematika.

\section{DAFTAR PUSTAKA}

Cahyani, P. D. (2018). Implementasi model pembelajaran accelerated learning type MASTER untuk meningkatkan kemampuan berpikir kritis. Skripsi. Surakarta: Universitas Muhammadiyah Surakarta.

Fauziah, F., Winarti, E., \& Kartono K. (2017). The effectiveness of SAVI learning in achieving communication ability and mathematical disposition for eighth grader, Unnes Journal of Mathematic Education, 6(1), 1-9.

Herawati, L. (2017). Peningkatan kemampuan koneksi matematik peserta didik menggunakan model problem based learning (PBL) dengan berbantuan software geogebra, Jurnal Penelitian Pendidikan dan Pengajaran Matematika, 3(1), 39-44. 
Killpatrick, J., Swafford, \& B. Findell. (2001). Adding it up: helping children learn mathematics. United States: The National Academies Press.

Muslim, A. P. (2016). Penerapan TAPPS disertai hypnoteaching (hypnoTAPPS) dalam meningkatkan disposisi matematis siswa SMP. Jurnal Pendidikan UNSIKA, 4(1), 1-16.

Naryaningsih, P. D. (2018). Pengembangan multiplayer game untuk melatihkan kemampuan koneksi dan disposisi matematis. Skripsi. Surabaya: UIN Sunan Ampel Surabaya.

Nizaruddin, Muhtarom \& Sugiyanti. (2017). Learning mathematics with traditional game "jirak": impact on mathematics disposition and students' achievement, International Conference on Mathematics: Education, Theory, and Application (ICMETA), Proceeding ICMETA, 1(1), 134-140.

Purwaningrum, J. P. (2016). Disposisi matematis siswa SD melalui model pembelajaran thinking aloud pairs problem solving. Suska Journal of Mathematics Education, 2(2), 125-130.

Rahman, T. (2015). Pengaruh pembelajaran penemuan terbimbing terhadap peningkatan kemampuan penalaran, komunikasi, dan disposisi matematis siswa. Skripsi. Bandung: Universitas Pendidikan Indonesia.

Risti D., Putri. dkk. (2018). Hubungan disposisi matematis terhadap kemampuan komunikasi matematis siswa kelas VII di SMP negeri 24 Jakarta”, Jurnal Pendidikan Matematika dalam Seminar Nasional 2018. 1. E-ISSN: 24774812.

Saputra, B. M. (2015). Penerapan model pembelajaran active learning tipe firing line untuk meningkatkan aktivitas dan prestasi belajar siswa kelas VII F SMP negeri 36 Purworejo tahun ajaran 2015/2016. Skripsi. Purworejo: Universitas Muhammadiyah Purworejo.

Sari, S. L., Masykur, R., \& Putra, R. W. Y. (2018). Penerapan strategi the firing line terhadap peningkatan kemampuan pemahaman konsep matematis siswa SMP. AKSIOMA: Jurnal Pendidikan Matematika FKIP Univ. Muhammadiyah Metro, 7(2), 229-236.

Sugandi, A. I. (2015). Penerapan pendekatan kontekstual untuk meningkatkan kemampuan komunikasi dan pemecahan masalah serta disposisi matematis siswa SMA. Paper presented at Seminar Nasional Matematika dan Pendidikan Matematika UNY, Yogyakarta. 